Check for updates

Cite this: RSC Adv., 2018, 8, 38980

\title{
Understanding the effects of vicinal carbon substituents and configuration on organofluorine hydrogen-bonding interaction $\uparrow$
}

\begin{abstract}
Qingqing Jia, ${ }^{a}$ Qingzhong Li, (D) ${ }^{b}$ Mo Luo a and Hai-Bei Li (D) *a
An investigation of $\mathrm{C}-\mathrm{F} \cdots \mathrm{H}-\mathrm{O}$ hydrogen bonds in the complexes $\mathrm{CH}_{n} \mathrm{XCH}_{n} \mathrm{~F} \cdots \mathrm{H}_{2} \mathrm{O}(n=0,1,2 ; \mathrm{X}=\mathrm{H}, \mathrm{F}, \mathrm{Cl}$, $\mathrm{Br}$ ) was performed at the MP2/aug-cc-pVTZ level. We found that the electron-withdrawing halogen substituents on the vicinal carbon cause the fluorine atom, participating in the hydrogen bond formation, to be less negatively charged. Thus, the halogen groups weaken the strength of organofluorine hydrogen bond by inductive effect. The position of the substituents on the vicinal carbon affects the strength of the $\mathrm{C}-\mathrm{F} \cdots \mathrm{H}-\mathrm{O}$ interaction. Compared with that in other isomers, the electron withdrawing substituent in 1-fluoro-ethane with stagger conformation as well as in 1-fluoro-ethene with trans configuration much weakens the interaction of $\mathrm{C}-\mathrm{F} \cdots \mathrm{H}-\mathrm{O}$ due to the hyperconjugative interaction between $\sigma_{(\mathrm{C}-\mathrm{F})}$ and $\sigma_{(\mathrm{C}-\mathrm{X})}^{*}$. By analogy, the electron-donating ones could largely strengthen it. We found that there is a good linear relationship between electron density at the BCP of F $\cdots \mathrm{H}$ and Wiberg bond indexes (WBI) as well as between natural bond-bond polarizability (NBBP) and WBI, which indicates that the magnitude of NBBP and WBI could be a good indicator of the hydrogen bond strength.
\end{abstract}

Received 30th September 2018 Accepted 15th November 2018

DOI: 10.1039/c8ra08122k

rsc.li/rsc-advances
Karanam and Choudhury reported that the fluorinated azobenzenes prefer to pack in the lattice by forming $\mathrm{C}-\mathrm{H} \cdots \mathrm{F}-\mathrm{C}\left(\mathrm{sp}^{2}\right)$ hydrogen bonds rather than by $\mathrm{C}-\mathrm{F} \cdots \mathrm{F}-\mathrm{C}, \mathrm{C}-\mathrm{F} \cdots \pi$, and $\pi \cdots \pi$ interactions, while the chlorinated and brominated analogues favor the latter interactions. ${ }^{11}$ This indicates that the strength of hydrogen bonds involving organic halogen atom is in the order of $\mathrm{F}>\mathrm{Cl}>\mathrm{Br}$, whereas it is in the reverse order for the halogen bonds. And their studies show that the strength of $\mathrm{C}-\mathrm{H} \cdots \mathrm{F}-$ $\mathrm{C}\left(\mathrm{sp}^{2}\right)$ is very small in the range from -0.8 to $-1.0 \mathrm{kcal} \mathrm{mol}^{-1}$. Dalvit and Vulpetti discovered a correlation between the NMR chemical shift of ${ }^{19} \mathrm{~F}$ and the strength of $\mathrm{C}-\mathrm{F} \cdots \mathrm{H}-\mathrm{X}$ interaction by running a statistical analysis of the CSD X-ray crystal structures of fluorinated molecules. ${ }^{12}$ Upon the basis of this correlation, they pointed out the organofluorine hydrogen bond is relevant for the molecular recognition mechanism and the stabilization of a preferred conformation. Undoubtedly, the strength of hydrogen bond is related to the nature of the hydrogen-bond donor and acceptor. Panini and Chopra have confirmed that the interaction of $\mathrm{C}\left(\mathrm{sp}^{2}\right)-\mathrm{H} \cdots \mathrm{F}-\mathrm{C}\left(\mathrm{sp}^{2} / \mathrm{sp}^{3}\right)$ is stronger than that of $\mathrm{C}\left(\mathrm{sp}^{3}\right)-\mathrm{H} \cdots \mathrm{F}-\mathrm{C}\left(\mathrm{sp}^{2} / \mathrm{sp}^{3}\right)$, which indicates $\mathrm{C}\left(\mathrm{sp}^{2}\right)-\mathrm{H}$ is a better donor than $\mathrm{C}\left(\mathrm{sp}^{3}\right)-\mathrm{H}$; Similarly, they also found that $\mathrm{C}\left(\mathrm{sp}^{2} / \mathrm{sp}^{3}\right)-\mathrm{H} \cdots \mathrm{F}-\mathrm{C}\left(\mathrm{sp}^{3}\right)$ is more stable than $\mathrm{C}\left(\mathrm{sp}^{2} /\right.$ $\left.\mathrm{sp}^{3}\right)-\mathrm{H} \cdots \mathrm{F}-\mathrm{C}\left(\mathrm{sp}^{2}\right)$, implying $\mathrm{C}\left(\mathrm{sp}^{3}\right)-\mathrm{F}$ is a better acceptor than $\mathrm{C}\left(\mathrm{sp}^{2}\right)-\mathrm{F} .^{13}$ Paquin group ${ }^{14}$ thoroughly reviewed the characteristics and properties of the intermolecular and intramolecular $\mathrm{C}-\mathrm{F} \cdots \mathrm{H}-\mathrm{X}$ interactions with $\mathrm{C}\left(\mathrm{sp}^{2} / \mathrm{sp}^{3}\right)-\mathrm{F}$ as hydrogen-bond acceptor and $\mathrm{O}-\mathrm{H}, \mathrm{N}-\mathrm{H}, \mathrm{C}\left(\mathrm{sp}^{2} / \mathrm{sp}^{3}\right)-\mathrm{H}$ as donor. In their studies, the presence of the organofluorine hydrogen bonds has been proved by spectroscopic experimental techniques and 
theoretical analysis. They figured out that organofluorine hydrogen bonds would have an impact on the chemical behaviors, like some measurable chemical equilibrium, such as acidity/basicity, preferential conformation, and reactivity.

As early as 1996, the hybridization of carbon atom in $\mathrm{C}-\mathrm{F}$ bond affecting the strength of hydrogen bonds has been raised. Howard et al. ${ }^{6}$ performed a theoretical calculation of $\mathrm{C}-\mathrm{F} \cdots \mathrm{H}-\mathrm{O}$ hydrogen bonds between $\mathrm{H}_{2} \mathrm{O}$ and $\mathrm{CH}_{3} \mathrm{~F} / \mathrm{CH}_{2} \mathrm{CHF}$. They found that the $\mathrm{C}\left(\mathrm{sp}^{3}\right)-\mathrm{F}$ fluorine is a better hydrogen bonds acceptor than $\mathrm{C}\left(\mathrm{sp}^{2}\right)-\mathrm{F}$ fluorine. Subsequently, the hybridization effect of $\mathrm{C}$ atom on the strength of $\mathrm{C}\left(\mathrm{sp}^{n}\right)-\mathrm{F} \cdots \mathrm{H}-\mathrm{F}(n=1,2$, and 3$)$ hydrogen bonds was studied in the complexes $\mathrm{CH}_{3} \mathrm{~F} \cdots \mathrm{HF}$, $\mathrm{CH}_{2} \mathrm{CHF} \cdots \mathrm{HF}$ and $\mathrm{CHCF} \cdots \mathrm{HF}$, which confirms that the hydrogen-bond acceptor ability of $\mathrm{C}-\mathrm{F}$ increases in the order: $\mathrm{C}(\mathrm{sp})-\mathrm{F}<\mathrm{C}\left(\mathrm{sp}^{2}\right)-\mathrm{F}<\mathrm{C}\left(\mathrm{sp}^{3}\right)-\mathrm{F} .{ }^{15}$ Masoodi et al. ${ }^{16}$ further studied the effects of carbon hybridization and halogen-acceptor type on some NMR data of HF which is hydrogen bond donor in the complex. They found that the proton shielding tensor of $\mathrm{HF}$ increases as $\mathrm{C}\left(\mathrm{sp}^{3}\right)<\mathrm{C}\left(\mathrm{sp}^{2}\right)<\mathrm{C}(\mathrm{sp})$, while this trend for fluorine in $\mathrm{HF}$ depends on the halogen-acceptor type. For organofluorine hydrogen bond, it is in the order of $\mathrm{C}\left(\mathrm{sp}^{3}\right)>\mathrm{C}\left(\mathrm{sp}^{2}\right)>$ $\mathrm{C}(\mathrm{sp})$. Giuffredi et $a .^{17}$ provided the experimental evidence demonstrating that the group - $\mathrm{CHF}$ is a better hydrogen bond acceptor than $-\mathrm{CF}_{2}$. This indicates that the proximal withdrawing electronic substituents weaken the strength of the organofluorine hydrogen bond, which illustrates the strength of the organofluorine hydrogen bond could be modulated by the proximal substituents. However, it is possible for the proximal substituent to largely influence the properties of $\mathrm{C}-\mathrm{F}$ bond, and then affects the other processes involving fluorine, such as chemical reactions and drug design. Until now, the investigation about the effects of the vicinal substituents on the properties of $\mathrm{C}\left(\mathrm{sp}^{n}\right)-\mathrm{F} \cdots \mathrm{H}-\mathrm{X}$ interaction is scarce. Exploring the role of the vicinal substituents on this interaction is necessary to fully understand the nature of organofluorine hydrogen bonds, especially for the modulation of its strength via the substitution at the vicinal carbon.

In the present work, we take water as proton donor and the derivatives of 1-fluoro-ethane, 1-fluoro-ethene, and 1-fluoroethyne as proton acceptor, that is, the complexes are $\mathrm{CH}_{n}$ $\mathrm{XCH}_{n} \mathrm{~F} \cdots \mathrm{H}_{2} \mathrm{O}(n=0,1,2 ; \mathrm{X}=\mathrm{H}, \mathrm{F}, \mathrm{Cl}, \mathrm{Br})$. We carried out $a b$ initio calculations to place a particular emphasis on understanding the effect of the vicinal substituents on the interaction of $\mathrm{C}\left(\mathrm{sp}^{n}\right)-\mathrm{F} \cdots \mathrm{H}-\mathrm{O}$ hydrogen bond. Furthermore, through the study of cis/trans isomer in CHXCHF and gauche/stagger isomer in $\mathrm{CH}_{2} \mathrm{XCH}_{2} \mathrm{~F}$, we evaluate the effect of the position of vicinal substituents on the interaction, and this will play important roles in many chemical processes, ${ }^{18}$ such as chemical enantiomeric selectivity and molecular recognition.

\section{Theoretical methods}

All structures were fully optimized at the level of MP2/aug-ccpVTZ using the Gaussian 09 program, Revision D.01. ${ }^{19}$ The frequency calculations were performed to confirm the optimized structures being the local minimum on the potential surfaces. To eliminate the effects of basis set superposition error (BSSE), the approach of counterpoise proposed by Boys and Bernardi ${ }^{20}$ was performed in the optimization as well as in the calculation of the interaction energy. Upon the basis of Bader's atoms in molecules (AIM) theory, ${ }^{21}$ the properties of bond critical points (BCPs) referring to the organofluorine hydrogen bond were calculated using AIM2000 program $^{22}$ at the same level with optimization. The natural bond orbital $(\mathrm{NBO})^{23}$ analysis was applied to evaluate the hyperconjugation energy, natural bond-bond polarization (NBBP), and Wiberg bond index (WBI) related to the region of the hydrogen bond interaction using the NBO 6.0 program ${ }^{24}$ at the HF/aug-cc-pVTZ level. Noncovalent interaction (NCI) index and molecular electrostatic potential analyses were finished via the Multiwfn program ${ }^{25}$ with the isosurface maps rendered by VMD1.9.3 software. ${ }^{26}$

\section{Results and discussion}

\subsection{Geometrical parameters and interaction energy}

Fig. 1 presents the optimized geometries of the complexes $\mathrm{CH}_{n} \mathrm{XCH}_{n} \mathrm{~F} \cdots \mathrm{H}_{2} \mathrm{O}(n=0,1,2 ; \mathrm{X}=\mathrm{H}, \mathrm{F}, \mathrm{Cl}, \mathrm{Br})$. Here, CA, CE, and $\mathrm{CY}$ stand for the complexes of 1-fluoro-ethane, 1-fluoroethene, and 1-fluoro-ethyne, respectively. Depending on the position of the vicinal substituents, the derivative of 1-fluoroethane has gauche and stagger conformations, and that of 1fluoro-ethene with cis and trans configurations. This leads to the formation of two and three structures for complexes CA and CE, respectively. It is evident from Fig. 1 that the $\mathrm{C}-\mathrm{F} \cdots \mathrm{H}-\mathrm{O}$ and $\mathrm{C}-$ $\mathrm{H} \cdots \mathrm{O}-\mathrm{H}$ hydrogen bonds coexist in the CA and $\mathrm{CE}$ complexes. The distances of $\mathrm{C}-\mathrm{F} \cdots \mathrm{H}-\mathrm{O}$ for $\mathrm{CA}-1-\mathrm{H}, \mathrm{CE}-1-\mathrm{H}$, and $\mathrm{CE}-2-\mathrm{H}$ are 2.011, 2.130, and 2.198 $\AA$ (Table 1), respectively, which is much less than the sum of the van der Waals atomic radius of $\mathrm{F}(1.47$ $\AA$ ) and $\mathrm{H}(1.20 \AA) .{ }^{27}$ In CA-1-H and CE-1-H, the angle of $\mathrm{O}-\mathrm{H} \cdots \mathrm{F}$ is close to $150^{\circ}$. This value decreases to $\sim 130^{\circ}$ in CE-2-H due to the steric effect, where the proton acceptor of $\mathrm{C}-\mathrm{F} \cdots \mathrm{H}-\mathrm{O}$ and proton donor of $\mathrm{C}-\mathrm{H} \cdots \mathrm{O}-\mathrm{H}$ connect to the same carbon atom (Fig. 1). The interaction of $\mathrm{C}-\mathrm{F} \cdots \mathrm{H}-\mathrm{O}$ results in the redshift of $\mathrm{O}-\mathrm{H}$ stretching vibrational frequency. All these geometrical parameters figure out that the $\mathrm{C}-\mathrm{F} \cdots \mathrm{H}-\mathrm{O}$ interaction belongs to the conventional hydrogen bond.

In the complexes CA-1-H, CE-1-H, and CE-2-H, the C-H $\cdots \mathrm{O}-$ $\mathrm{H}$ interaction is confirmed by the presence of the bond critical point (BCP) between $\mathrm{H} \cdots \mathrm{O}$ contact based on the AIM analysis (see Section 3.3), and its weak strength is illustrated by noncovalent interaction analysis (see Section 3.2). Thus, the C$\mathrm{H} \cdots \mathrm{O}-\mathrm{H}$ interaction makes a limited contribution to the total interaction energy. From Table 1, the total interaction energy of the complexes is larger than $3.00 \mathrm{kcal} \mathrm{mol}^{-1}$ in CA and CE. This indicates that the $\mathrm{sp}^{3}$ - and $\mathrm{sp}^{2}-\mathrm{C}-\mathrm{F}$ bonds in the fluorinated compounds are likely to form the organofluorine hydrogen bond with medium strength. In comparison with $\mathrm{sp}^{3}$ - and $\mathrm{sp}^{2}$ $\mathrm{C}-\mathrm{F}$, sp-C-F bond in $\mathrm{CHCF}$ is a very poor hydrogen bond acceptor according to the interaction energy $\left(0.56 \mathrm{kcal} \mathrm{mol}^{-1}\right)$ and the magnitude of $\Delta \nu(\mathrm{O}-\mathrm{H})$, which is consistent with the previous studies. ${ }^{15}$ This indicates that in the fluorinated compounds involving sp-C-F, the possibility to form the organofluorine hydrogen bond is small. Although the strength of the sp-C-F $\cdots \mathrm{H}-\mathrm{O}$ interaction increases by the addition of the 


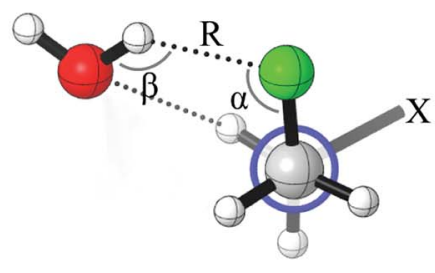

CA-1

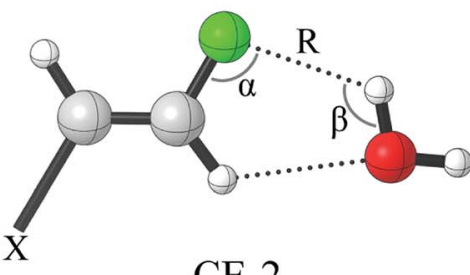

CE-2

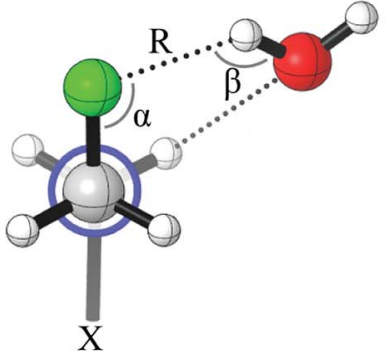

CA-2

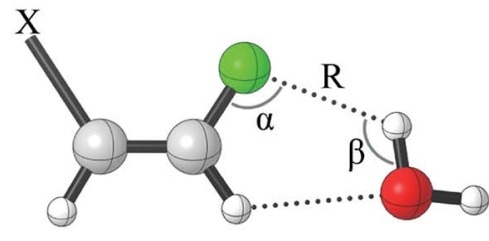

CE-3

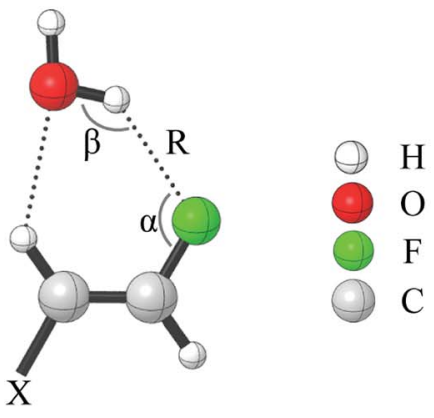

CE-1

Fig. 1 All optimized structures of $\mathrm{CH}_{n} \mathrm{XCH}_{n} \mathrm{~F} \cdots \mathrm{H}_{2} \mathrm{O}(n=0,1,2 ; \mathrm{X}=\mathrm{H}, \mathrm{F}, \mathrm{Cl}, \mathrm{Br})$.

Table 1 Optimized geometries ${ }^{a}$ and interaction energies $(\Delta E$, in $\mathrm{kcal} \mathrm{mol}^{-1}$ ) of the complexes

\begin{tabular}{lllllll}
\hline Complexes & $\mathrm{X}$ & $\alpha$ & $\beta$ & $\mathrm{R}(\mathrm{F} \cdots \mathrm{H})$ & $\Delta \nu(\mathrm{O}-\mathrm{H})$ & $\Delta E$ \\
\hline CA-1-X & $\mathrm{H}$ & 102.4 & 147.2 & 2.011 & -46.2 & -4.37 \\
& $\mathrm{~F}$ & 101.1 & 135.0 & 2.087 & -35.3 & -4.66 \\
& $\mathrm{Cl}$ & 102.0 & 134.8 & 2.088 & -35.4 & -4.78 \\
& $\mathrm{Br}$ & 102.2 & 135.4 & 2.086 & -35.5 & -4.81 \\
& $\mathrm{CH}_{3}$ & 103.4 & 149.2 & 2.001 & -47.8 & -4.34 \\
& $\mathrm{NH}_{2}$ & 104.3 & 147.5 & 2.000 & -50.8 & -4.75 \\
& $\mathrm{NO}_{2}$ & 101.1 & 126.6 & 2.177 & -26.9 & -4.97 \\
$\mathrm{CA}-2-\mathrm{X}$ & $\mathrm{H}$ & 102.4 & 147.2 & 2.011 & -46.2 & -4.37 \\
& $\mathrm{~F}$ & 103.2 & 135.0 & 2.099 & -29.3 & -4.07 \\
& $\mathrm{Cl}$ & 103.1 & 134.8 & 2.099 & -31.3 & -4.33 \\
& $\mathrm{Br}$ & 102.8 & 135.0 & 2.098 & -32.3 & -4.41 \\
$\mathrm{CE}-1-\mathrm{X}$ & $\mathrm{H}$ & 114.9 & 148.1 & 2.130 & -23.2 & -3.25 \\
& $\mathrm{~F}$ & 116.3 & 135.6 & 2.209 & -17.8 & -3.54 \\
& $\mathrm{Cl}$ & 116.2 & 135.0 & 2.223 & -17.9 & -3.48 \\
& $\mathrm{Br}$ & 115.8 & 135.3 & 2.225 & -18.5 & -3.50 \\
$\mathrm{CE}-2-\mathrm{X}$ & $\mathrm{H}$ & 102.1 & 130.2 & 2.198 & -18.1 & -3.20 \\
& $\mathrm{~F}$ & 100.9 & 121.0 & 2.309 & -13.1 & -3.10 \\
& $\mathrm{Cl}$ & 101.1 & 119.1 & 2.334 & -12.6 & -3.11 \\
& $\mathrm{Br}$ & 101.2 & 118.9 & 2.336 & -12.8 & -3.12 \\
$\mathrm{CE}-3-\mathrm{X}$ & $\mathrm{H}$ & 102.1 & 130.2 & 2.198 & -18.1 & -3.20 \\
& $\mathrm{~F}$ & 100.5 & 122.0 & 2.299 & -14.4 & -3.33 \\
& $\mathrm{Cl}$ & 100.9 & 120.2 & 2.322 & -13.9 & -3.34 \\
& $\mathrm{Br}$ & 101.0 & 119.9 & 2.327 & -14.0 & -3.34 \\
$\mathrm{CY}-\mathrm{X}$ & $\mathrm{H}$ & 122.9 & 153.2 & 2.375 & -2.8 & -0.56 \\
& $\mathrm{CH}{ }_{3}$ & 118.6 & 166.6 & 2.301 & -4.8 & -0.93
\end{tabular}

${ }^{a} \alpha$ is for $\angle \mathrm{C}-\mathrm{F} \cdots \mathrm{H}$, and $\beta$ is for $\angle \mathrm{O}-\mathrm{H} \cdots \mathrm{F}$, bond angles in degree; bond lengths in $\AA$; frequencies in $\mathrm{cm}^{-1}$.

electron-donating vicinal substituents, such as $\mathrm{CH}_{3}$ (Table 1), the addition of the electron-withdrawing vicinal halogen substituents results in the parallel arrangement of $\mathrm{O}-\mathrm{H}$ and $\mathrm{C}-\mathrm{F}$ bonds. This implies that there is no $\mathrm{sp}-\mathrm{C}-\mathrm{F} \cdots \mathrm{H}-\mathrm{O}$ hydrogen bond formation between $\mathrm{CXCF}(\mathrm{X}=\mathrm{F}, \mathrm{Cl}, \mathrm{Br})$ and $\mathrm{H}_{2} \mathrm{O}$. Thus, in the following section, we do not discuss the complexes involving $\mathrm{CXCF}$ ( $\mathrm{X}=\mathrm{F}, \mathrm{Cl}, \mathrm{Br})$.

The halogen substituents at the vicinal carbon weaken the $\mathrm{C}-\mathrm{F} \cdots \mathrm{H}-\mathrm{O}$ interaction, which is evidenced by the longer distance of $\mathrm{F} \cdots \mathrm{H}$ contact, the smaller angle of $\angle \mathrm{C}-\mathrm{F} \cdots \mathrm{H}$, and the less redshift of $\mathrm{O}-\mathrm{H}$ stretching vibrational frequencies compared with that of no vicinal halogen substituents (Table 1). This illustrates that the vicinal halogen substituents, like the proximal ones, ${ }^{17}$ weaken the ability of $\mathrm{C}-\mathrm{F}$ to act as a weak hydrogen-bond acceptor. We further add $-\mathrm{NO}_{2},-\mathrm{CH}_{3}$, and $-\mathrm{NH}_{2}$ groups at the vicinal carbon in $\mathrm{CA}-1$. As anticipated, with the more electron-withdrawing $-\mathrm{NO}_{2}$ substituent at the vicinal carbon, the $\mathrm{C}-\mathrm{F}$ bond is a weaker hydrogen-bond acceptor than that with halogen. On the contrary, the electron-donating groups strengthen the ability of $\mathrm{C}-\mathrm{F}$ to be a better hydrogenbond acceptor. The position of halogen atom, such as the gauche and stagger conformations in 1-fluoro-ethane, has slightly different effect on the $\mathrm{C}-\mathrm{F} \cdots \mathrm{H}-\mathrm{O}$ interaction. The magnitudes of the distance of $\mathrm{F} \cdots \mathrm{H}$ contact and the redshift of $\mathrm{O}-\mathrm{H}$ stretching vibrational frequencies indicate that the $\mathrm{C}-\mathrm{F} \cdots \mathrm{H}-\mathrm{O}$ interaction in the stagger conformation is slightly weaker than that in the gauche one. We attribute this to the hyperconjugative interaction $^{28-30}$ between $\sigma_{(\mathrm{C}-\mathrm{F})}$ and $\sigma_{(\mathrm{C}-\mathrm{X})}^{*}$, which delocalizes the electron density of fluorine atom. The similar trend is found for the trans and cis configuration in the 1-fluoro-ethene complexes, CE-2 and CE-3, respectively.

The halogen substituent plays duel role in the total interaction strength of the complexes. For C-F $\cdots \mathrm{H}-\mathrm{O}$ organofluorine hydrogen bonds, the vicinal halogen reduces its interaction strength. On the contrary, for $\mathrm{C}-\mathrm{H} \cdots \mathrm{O}-\mathrm{H}$ interaction, the electron-withdrawing halogen group is the proximal carbon substituent for proton donor $\mathrm{C}-\mathrm{H}$, and they increases the 


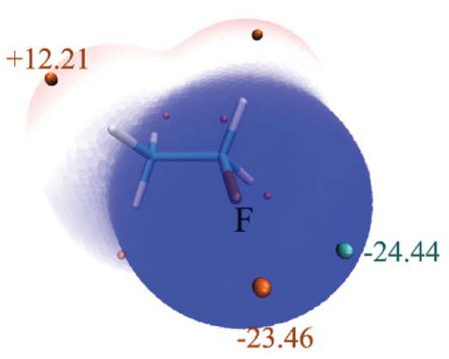

MA-H

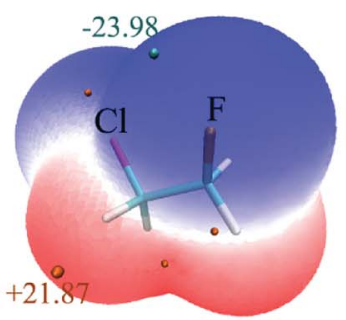

MA-1-Cl

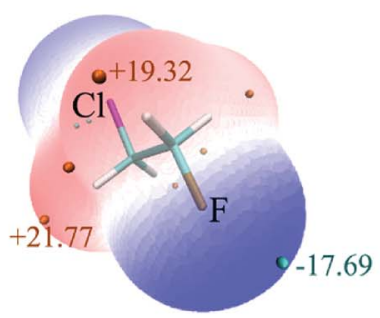

MA-2-Cl

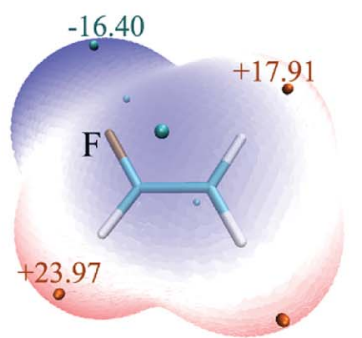

ME-H

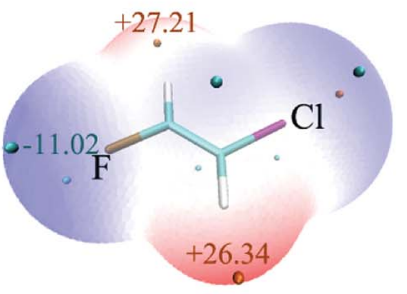

ME-1-C1

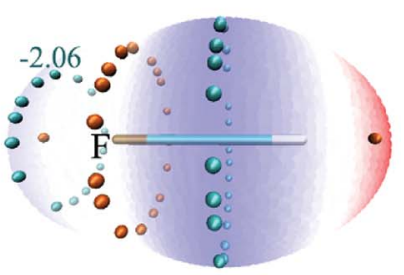

MY-H

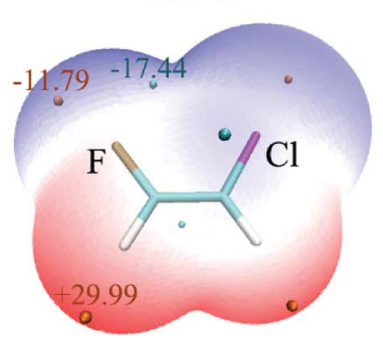

ME-2-Cl

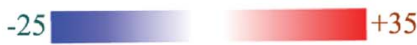

Fig. 2 ESP-mapped molecular vdW surface of optimized monomers, in $\mathrm{kcal} \mathrm{mol}^{-1}$. The elements of $\mathrm{F}$ and $\mathrm{Cl}$ were represented as ochre and purple, respectively.

strength of $\mathrm{C}-\mathrm{H} \cdots \mathrm{O}-\mathrm{H}$ interaction. ${ }^{31}$ It is evident from Table 1 that the interaction energy is slightly larger in CA-1-X, CE-1-X, and $\mathrm{CE}-3-\mathrm{X}(\mathrm{X}=\mathrm{F}, \mathrm{Cl}$, and $\mathrm{Br})$ than that in its no vicinal halogen substituent complex. This indicates that the influence of the halogen substituent on the strength of $\mathrm{C}-\mathrm{H} \cdots \mathrm{O}-\mathrm{H}$ is greater than that on $\mathrm{C}-\mathrm{F} \cdots \mathrm{H}-\mathrm{O}$. Differently, in CA-2-X and CE-2$\mathrm{X}$, the effect of the vicinal electron-withdrawing substituents on the strength of $\mathrm{C}-\mathrm{F} \cdots \mathrm{H}-\mathrm{O}$ is more significant than that on $\mathrm{C}-$ $\mathrm{H} \cdots \mathrm{O}-\mathrm{H}$, due to the hyperconjugative interaction between bonding and antibonding orbitals of $\mathrm{C}-\mathrm{F}$ and $\mathrm{C}-\mathrm{X}$ bonds.

\subsection{Molecular electrostatic potential and non-covalent interaction analysis}

Electrostatic potential (ESP) analysis is useful to study noncovalent interactions. ${ }^{32-34} \mathrm{~A}$ good correlation between the ability of hydrogen-bond acceptor and its molecular ESP minimum value $\left(V_{\text {min }}\right)$ has been confirmed..$^{35}$ Fig. 2 presents the ESP maps for the optimized monomers of $\mathrm{CH}_{n} \mathrm{XCH}_{n} \mathrm{~F}(n=0,1,2 ; \mathrm{X}=\mathrm{H}, \mathrm{Cl})$ on the van der Waals surface, ${ }^{36}$ in which MA, ME, and MY stand for the monomers, 1-fluoro-ethane, 1-fluoro-ethene, and 1-fluoroethyne, respectively. The surfaces were colored on a blue-white-
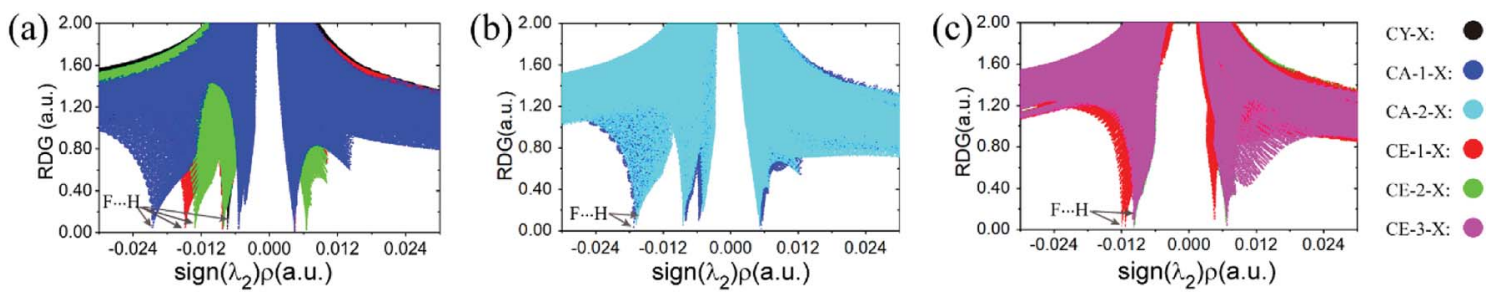

Fig. 3 Plots of the reduced density gradient, RDG, versus the electron density multiplied by the sign of the second Hessian eigenvalue, sign $\left(\lambda_{2}\right) \rho$ for complexes (a) CA-1-H, CE-1-H, CE-2-H, and CY-H; (b) CA-1-Cl and CA-2-Cl; (c) CE-1-Cl, CE-2-Cl, and CE-3-Cl. 

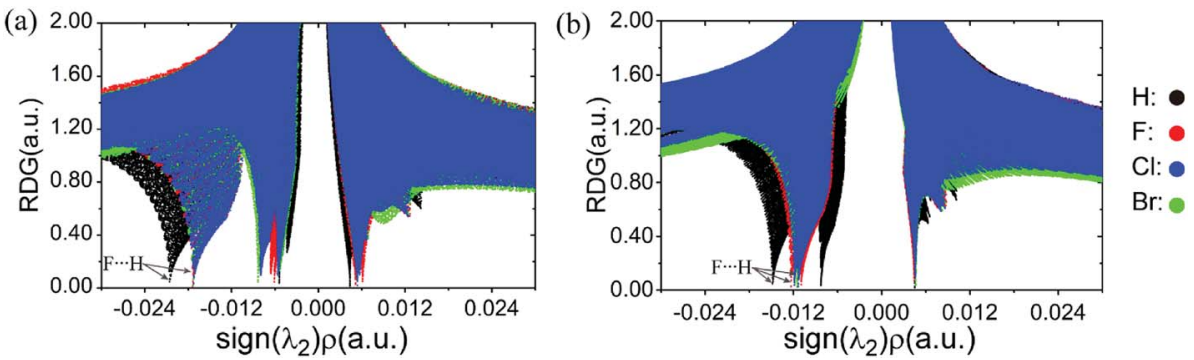

Fig. 4 Plots of the reduced density gradient, RDG, versus the electron density multiplied by the sign of the second Hessian eigenvalue, sign $\left(\lambda_{2}\right) \rho$ for complexes (a) CA-1-X and (b) CE-1-X.

Table 2 Local properties ${ }^{a}$ at BCP of $\mathrm{C}-\mathrm{F} \cdots \mathrm{H}-\mathrm{O}$ interaction and NBO parameters

\begin{tabular}{|c|c|c|c|c|c|c|c|}
\hline Complexes & $\mathrm{x}$ & $\rho(r)^{a}$ & $\nabla^{2} \rho(r)^{a}$ & $H^{a}$ & $\mathrm{NBBP}^{b}$ & $E^{(2) b}$ & WBI $(\mathrm{F} \cdots \mathrm{H})^{b}$ \\
\hline \multirow[t]{7}{*}{ CA-1-X } & $\mathrm{H}$ & 0.0180 & 0.076 & 0.0015 & 0.0087 & 3.16 & 0.0086 \\
\hline & $\mathrm{F}$ & 0.0154 & 0.070 & 0.0024 & 0.0059 & 1.90 & 0.0058 \\
\hline & $\mathrm{Cl}$ & 0.0153 & 0.070 & 0.0025 & 0.0057 & 1.87 & 0.0058 \\
\hline & $\mathrm{Br}$ & 0.0154 & 0.070 & 0.0024 & 0.0058 & 1.91 & 0.0059 \\
\hline & $\mathrm{CH}_{3}$ & 0.0184 & 0.078 & 0.0018 & 0.0092 & 3.45 & 0.0091 \\
\hline & $\mathrm{NH}_{2}$ & 0.0185 & 0.078 & 0.0019 & 0.0093 & 3.43 & 0.0091 \\
\hline & $\mathrm{NO}_{2}$ & 0.0128 & 0.060 & 0.0025 & 0.0034 & 1.08 & 0.0036 \\
\hline \multirow[t]{4}{*}{ CA-2-X } & $\mathrm{H}$ & 0.0180 & 0.076 & 0.0020 & 0.0087 & 3.16 & 0.0086 \\
\hline & $\mathrm{F}$ & 0.0149 & 0.067 & 0.0025 & 0.0051 & 1.76 & 0.0053 \\
\hline & $\mathrm{Cl}$ & 0.0149 & 0.068 & 0.0025 & 0.0053 & 1.75 & 0.0054 \\
\hline & $\mathrm{Br}$ & 0.0150 & 0.068 & 0.0024 & 0.0053 & 1.78 & 0.0055 \\
\hline \multirow[t]{4}{*}{ CE-1-X } & $\mathrm{H}$ & 0.0130 & 0.057 & 0.0023 & 0.0043 & 1.55 & 0.0048 \\
\hline & $\mathrm{F}$ & 0.0110 & 0.051 & 0.0022 & 0.0025 & 0.85 & 0.0031 \\
\hline & $\mathrm{Cl}$ & 0.0107 & 0.049 & 0.0021 & 0.0023 & 0.76 & 0.0029 \\
\hline & $\mathrm{Br}$ & 0.0106 & 0.049 & 0.0021 & 0.0023 & 0.76 & 0.0029 \\
\hline \multirow[t]{4}{*}{ CE-2-X } & $\mathrm{H}$ & 0.0117 & 0.055 & 0.0015 & 0.0029 & 0.94 & 0.0034 \\
\hline & $\mathrm{F}$ & 0.0095 & 0.045 & 0.0021 & 0.0015 & 0.45 & 0.0021 \\
\hline & $\mathrm{Cl}$ & 0.0091 & 0.043 & 0.0020 & 0.0013 & 0.38 & 0.0019 \\
\hline & $\mathrm{Br}$ & 0.0091 & 0.043 & 0.0020 & 0.0013 & 0.37 & 0.0019 \\
\hline \multirow[t]{4}{*}{ CE-3-X } & $\mathrm{H}$ & 0.0117 & 0.055 & 0.0015 & 0.0029 & 0.94 & 0.0034 \\
\hline & $\mathrm{F}$ & 0.0097 & 0.046 & 0.0021 & 0.0016 & 0.47 & 0.0021 \\
\hline & $\mathrm{Cl}$ & 0.0093 & 0.044 & 0.0020 & 0.0014 & 0.41 & 0.0019 \\
\hline & $\mathrm{Br}$ & 0.0092 & 0.044 & 0.0020 & 0.0014 & 0.39 & 0.0019 \\
\hline \multirow[t]{2}{*}{ CY-X } & $\mathrm{H}$ & 0.0066 & 0.030 & 0.0015 & 0.0008 & 0.33 & 0.0013 \\
\hline & $\mathrm{CH}_{3}$ & 0.0080 & 0.036 & 0.0015 & 0.0014 & 0.60 & 0.0019 \\
\hline
\end{tabular}

${ }^{a}$ Electron density, $\rho(r)$, the Laplacian of the electron density, $\nabla^{2} \rho(r)$ and the total electron energy density $H$ at BCP of $\mathrm{F} \cdots \mathrm{H}$. All are in a.u. ${ }^{b}$ Natural bond-bond polarizability (NBBP, in a.u.) between $\mathrm{O}-\mathrm{H}$ and $\mathrm{C}-\mathrm{F}$ as well as the lone pairs of F, Wiberg bond index (WBI, in a.u.) of $\mathrm{F} \cdots \mathrm{H}$, second-order perturbation energy $\left(E^{(2)}, \mathrm{kcal} \mathrm{mol}^{-1}\right)$ containing $n_{\mathrm{F}} \rightarrow \sigma_{(\mathrm{O}-\mathrm{H})}^{*}$ and $\sigma_{(\mathrm{C}-\mathrm{F})} \rightarrow \sigma_{(\mathrm{O}-\mathrm{H})}^{*}$.

red scale according to the values of ESP. It is evident that the local $V_{\min }$ of fluorine atom shows the dramatic decrease from -24.44 , -16.40 to $-2.06 \mathrm{kcal} \mathrm{mol}^{-1}$ (MA-H, ME-H, and MY-H in Fig. 2, respectively) with the increase of s-character for $\mathrm{sp}^{3}-\mathrm{sp}^{2}-$, and $\mathrm{sp}$ $\mathrm{C}$ atom. The variation of these local $V_{\min }$ values on fluorine atom are consistent with that of the $\mathrm{sp}^{n}-\mathrm{C}-\mathrm{F} \cdots \mathrm{H}-\mathrm{O}$ interaction strength. As anticipated, the electron withdrawing characteristic of the halogen groups decreases the local EPS of F, especially in the stagger conformation, MA-2, and trans configuration, ME-1 (Fig. 2). On the contrary, the electron-donating groups increases it (Fig. S1†). This correlation illustrates the electrostatic character of the organofluorine hydrogen bonds.
The non-covalent interaction approach, proposed by Yang et al. ${ }^{37}$ is widely used to study hydrogen bond interactions ${ }^{38-40}$ by the isosurface of the reduced density gradient (RDG). It has been confirmed that the result is insensitive to the computational level. ${ }^{37}$ The RDG analysis has been performed via Multiwfn program at B3LYP/6-31G* level. The scatter diagrams, $\operatorname{sign}\left(\lambda_{2}\right) \rho$ versus RDG, have shown in Fig. 3 and 4 . The spikes representing $\mathrm{C}-\mathrm{F} \cdots \mathrm{H}-\mathrm{O}$ interaction were marked by arrows, and the left ones with $\operatorname{sign}\left(\lambda_{2}\right) \rho$ smaller than zero stand for the interaction of $\mathrm{C}-\mathrm{H} \cdots \mathrm{O}-\mathrm{H}$. It is apparent from Fig. 3 and 4 that the strength of $\mathrm{C}-\mathrm{F} \cdots \mathrm{H}-\mathrm{O}$ organofluorine hydrogen bond is much stronger than that of the $\mathrm{C}-\mathrm{H} \cdots \mathrm{O}-\mathrm{H}$ in the complexes, particularly in the $\mathrm{CH}_{3} \mathrm{CH}_{2} \mathrm{~F} \cdots \mathrm{H}_{2} \mathrm{O}$. The spike values for $\mathrm{sp}^{n}-\mathrm{C}-$ $\mathrm{F} \cdots \mathrm{H}-\mathrm{O}$ interaction implies the hybridization of carbon atom significantly affects the interaction strength (Fig. 3a). The ability of $\mathrm{F}$ atom as proton acceptor is in the order: $\mathrm{C}\left(\mathrm{sp}^{3}\right)-\mathrm{F}>\mathrm{C}\left(\mathrm{sp}^{2}\right)-\mathrm{F}$ $>\mathrm{C}$ (sp)-F. Similarly, the position of the spikes for vicinal Clsubstituent complexes (Fig. $3 \mathrm{~b}$ and c) is consistent with the strength of $\mathrm{C}-\mathrm{F} \cdots \mathrm{H}-\mathrm{O}$ in the gauche and stagger isomers $\mathrm{CA}-1-\mathrm{Cl}$ and $\mathrm{CA}-2-\mathrm{Cl}$, respectively, as well as in the trans and cis isomers CE-1-Cl, CE-2-Cl, and CE-3-Cl. The same case is for other halogen-substituents (see Fig. S2 $\dagger$ ). The vicinal halogensubstituents generally weaken the interaction of $\mathrm{C}-\mathrm{F} \cdots \mathrm{H}-\mathrm{O}$, indicated by the right shift of spikes for $\mathrm{F}-, \mathrm{Cl}-$, and $\mathrm{Br}$ substituent complexes compared with that in CA-1-H and CE1-H (Fig. 4a and b). And in CA-1-X and CE-1-X, the close spike values for $\mathrm{C}-\mathrm{F} \cdots \mathrm{H}-\mathrm{O}$ interaction with vicinal $\mathrm{F}-, \mathrm{Cl}-$, and $\mathrm{Br}-$ substituent illustrate that the effect of vicinal halogensubstituent on the strength of $\mathrm{C}-\mathrm{F} \cdots \mathrm{H}-\mathrm{O}$ is similar. This is in accordance with the approximately equal values of both $\Delta \nu(\mathrm{O}-$ $\mathrm{H}$ ) and the distance of $\mathrm{F} \cdots \mathrm{H}$ contact, respectively, in CA-1-X and CE-1-X (Table 1). This demonstrates that the electron withdrawing halogen group at the vicinal carbon affects the strength of the $\mathrm{C}-\mathrm{F} \cdots \mathrm{H}-\mathrm{O}$ interaction by inductive effect. However, due to the long distance transmission of electron, the inductive effect of F-, Cl-, and Br-substituent on the strength of $\mathrm{C}-\mathrm{F} \cdots \mathrm{H}-\mathrm{O}$ is comparative.

\subsection{AIM and NBO analysis}

The quantum theory of atoms in molecules (QTAIM) proposed by Bader $^{21}$ provides a powerful tool to investigate the properties of hydrogen bonds. A set of criteria have been proposed to characterize hydrogen bonds. ${ }^{\mathbf{4 1 , 4 2}}$ The molecular graphs involving the BCPs in the complexes were presented in Fig. S3. $\dagger$ 
(a)

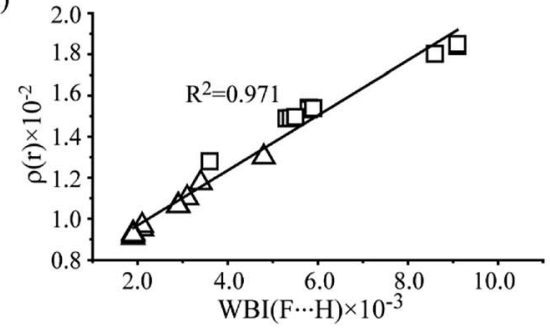

(b)

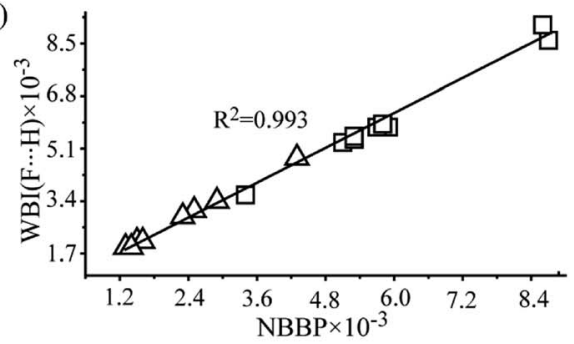

Fig. 5 (a) The relationship between the Wiberg bond indexes (WBI) and the electron density $(\rho)$ at the bond critical points of F ...H. (b) The relationship between natural bond-bond polarizability indices (NBBP) and WBI (F $\cdots H$ ). Hollow squares and triangles stand for $\mathrm{C}\left(\mathrm{sp}^{3}\right)-\mathrm{F} \cdots \mathrm{H}$ and $\mathrm{C}\left(\mathrm{sp}^{2}\right)-\mathrm{F} \cdots \mathrm{H}$, respectively.

The local properties at the BCPs of $\mathrm{C}-\mathrm{F} \cdots \mathrm{H}-\mathrm{O}$ were listed in Table 2. Koch and Popelier ${ }^{\mathbf{4 1}}$ proposed that the most important indicator to assess the existence of hydrogen bonds is the values of electron density and its Laplacian $\left(\nabla^{2} \rho(r)\right)$ at the BCPs. They proposed that the electron density falls within 0.002 to 0.04 a.u. and the $\nabla^{2} \rho(r)$ ranges from 0.02 to 0.15 a.u. for the evidence of the existence of hydrogen bonds. In this work, the electron density at the BCPs is in the range from 0.007 to 0.018 a.u., and the $\nabla^{2} \rho(r)$ is from 0.03 to 0.076 a.u. (Table 2), both of which lie within the range proposed by Koch and Popelier. Moreover, the $\nabla^{2} \rho(r)$ as well as the total electronic energy density, $\mathrm{H}$, is positive, indicating that $\mathrm{C}-\mathrm{F} \cdots \mathrm{H}-\mathrm{O}$ interaction is weak hydrogen bond upon the basis of the hydrogen bond classification proposed by Rozas et al. ${ }^{42}$

The second-order perturbation energy $E^{(2)}$ of the NBO analysis in Table 2 is the sum of interaction energy from the lone pairs of $\mathrm{F}$ and the bonding orbital of $\mathrm{C}-\mathrm{F}, \sigma_{(\mathrm{C}-\mathrm{F})}$, to the antibonding orbital of $\mathrm{O}-\mathrm{H}, \sigma_{(\mathrm{O}-\mathrm{H})}^{*}$. It is evident from Table 2 that the $E^{(2)}$ in the complexes with vicinal halogen substituent is nearly one time less than that with no vicinal substituent. This implicates that the vicinal substituents largely affect the charge transfer from orbitals of the proton acceptor to ones of the proton donor. We calculate the WBI and NBBP indices referring to the region of hydrogen bond formation by the NBO analysis. WBI is a parameter to measure the strength between two atoms, and NBBP is a quantitative descriptor for the electronic delocalization effect. In this work, WBI is referred to the $\mathrm{F} \cdots \mathrm{H}$, and the magnitude of NBBP is the sum of $n_{\mathrm{F}} \leftrightarrow \sigma_{(\mathrm{O}-\mathrm{H})}$ and $\sigma_{(\mathrm{C}-\mathrm{F})} \leftrightarrow$ $\sigma_{(\mathrm{O}-\mathrm{H})}$. Fig. 5 depicts the relationships among the WBI, electron density and NBBP. As this figure illustrates, the electron density at the BCPs of ${ }^{\cdots} \cdot \mathrm{H}$ and WBI, as well as the NBBP and WBI, have good linear relationships. This indicates that like the electron density, the magnitude of WBI and NBBP, in which the latter is the sum of NBBPs referred to the bonds directly participating in the hydrogen bond formation, could be a good indicator of the hydrogen bond strength. This would be useful for the estimation of the intramolecular hydrogen bond strength as well as the single intermolecular hydrogen bond strength in the system, where several hydrogen bonds coexist.

\section{Conclusions}

The $\mathrm{C}-\mathrm{F} \cdots \mathrm{H}-\mathrm{O}$ hydrogen bonds in the complexes $\mathrm{CH}_{n} \mathrm{XCH}_{n} \mathrm{~F} \cdots$ $\mathrm{H}_{2} \mathrm{O}(n=0,1,2 ; \mathrm{X}=\mathrm{H}, \mathrm{F}, \mathrm{Cl}, \mathrm{Br})$ have been studied at the MP2/
aug-cc-pVTZ level. In the derivatives of 1-fluoro-ethane and 1fluoro-ethene, besides the $\mathrm{C}-\mathrm{F} \cdots \mathrm{H}-\mathrm{O}$ hydrogen bonds, the $\mathrm{C}-$ $\mathrm{H} \cdots \mathrm{O}-\mathrm{H}$ interaction also exist. We found that the halogen substituents at the vicinal carbon, similarly with that at the proximal carbon, reduce the ability of the $\mathrm{F}$ atom to act as a hydrogen bond acceptor. Differently, the influence of the vicinal carbon substituents to a certain degree is less than that of the proximal ones. Our results show that the halogen group at the vicinal carbon affects the interaction strength of $\mathrm{C}-\mathrm{F} \cdots \mathrm{H}-\mathrm{O}$ by inductive effect, and due to the long distance transmission of electron, the inductive effect of the vicinal $\mathrm{F}-, \mathrm{Cl}-$, and $\mathrm{Br}-$ substituent on the interaction strength is comparative. Compared with other structures, the stagger conformation in 1fluoro-ethane and the trans configuration in 1-fluoro-ethene more affect the interaction of the $\mathrm{C}-\mathrm{F} \cdots \mathrm{H}-\mathrm{O}$ due to the hyperconjugative interaction between $\sigma_{(\mathrm{C}-\mathrm{F})}$ and $\sigma_{(\mathrm{C}-\mathrm{X})}^{*}$. We found that the magnitude of both Wiberg bond indexes and natural bond-bond polarizability could be a good indicator of the strength of the hydrogen bond.

\section{Conflicts of interest}

There are no conflicts to declare.

\section{Acknowledgements}

This work was supported by the National Science Foundation of China (21403127) and the Natural Science Foundation of Shandong Province, China (ZR2014BQ015). Hai-Bei Li thanks the fund of Young Scholars Program of Shandong University (Weihai), YSPSDUWH, and the supercomputing system in the Supercomputing Center, Shandong University, Weihai.

\section{References}

1 S. Purser, P. R. Moore, S. Swallow and V. Gouverneur, Chem. Soc. Rev., 2008, 37, 320-330.

2 R. Berger, G. Resnati, P. Metrangolo, E. Weber and J. Hulliger, Chem. Soc. Rev., 2011, 40, 3496-3508.

3 T. Furuya, A. S. Kamlet and T. Ritter, Nature, 2011, 473, 470477.

4 H. Amii and K. Uneyama, Chem. Rev., 2009, 109, 2119-2183. 5 D. O'Hagan, Chem. Soc. Rev., 2008, 37, 308-319. 
6 J. A. K. Howard, V. J. Hoy, D. O'Hagan and G. T. Smith, Tetrahedron, 1996, 52, 12613-12622.

7 J. D. Dunitz and R. Taylor, Chem.-Eur. J., 1997, 3, 89-98.

8 V. R. Thalladi, H. C. Weiss, D. Blaser, R. Boese, A. Nangia and

G. R. Desiraju, J. Am. Chem. Soc., 1998, 120, 8702-8710.

9 J. D. Dunitz, ChemBioChem, 2004, 5, 614-621.

10 E. Arunan, G. R. Desiraju, R. A. Klein, J. Sadlej, S. Scheiner,

I. Alkorta, D. C. Clary, R. H. Crabtree, J. J. Dannenberg,

P. Hobza, H. G. Kjaergaard, A. C. Legon, B. Mennucci and

D. J. Nesbitt, Pure Appl. Chem., 2011, 83, 1619-1636.

11 M. Karanam and A. R. Choudhury, Cryst. Growth Des., 2013, 13, 4803-4814.

12 C. Dalvit and A. Vulpetti, ChemMedChem, 2011, 6, 104-114. 13 P. Panini and D. Chopra, CrystEngComm, 2013, 15, 3711.

14 P. A. Champagne, J. Desroches and J. F. Paquin, Synthesis, 2015, 47, 306-322.

15 L. Chęcińska and S. J. Grabowski, Chem. Phys., 2006, 327, 202-208.

16 H. R. Masoodi, A. Ebrahimi and M. Habibi, Chem. Phys. Lett., 2009, 483, 43-48.

17 G. T. Giuffredi, V. Gouverneur and B. Bernet, Angew. Chem., Int. Ed., 2013, 52, 10524-10528.

18 M. Guizado-Rodriguez, A. Ariza-Castolo, G. Merino, A. Vela, H. Noth, V. I. Bakhmutov and R. Contreras, J. Am. Chem. Soc., 2001, 123, 9144-9152.

19 M. J. Frisch, G. W. Trucks, H. B. Schlegel, G. E. Scuseria, J. R. C. M. A. Robb, G. Scalmani, V. Barone, B. Mennucci, H. N. G. A. Petersson, M. Caricato, X. Li, H. P. Hratchian, J. B. A. F. Izmaylov, G. Zheng, J. L. Sonnenberg, M. Hada, K. T. M. Ehara, R. Fukuda, J. Hasegawa, M. Ishida, T. Nakajima, O. K. Y. Honda, H. Nakai, T. Vreven, J. A. Montgomerya Jr, F. O. J. E. Peralta, M. Bearpark, J. J. Heyd, E. Brothers, V. N. S. K. N. Kudin, T. Keith, R. Kobayashi, J. Normand, A. R. K. Raghavachari, J. C. Burant, S. S. Iyengar, J. Tomasi, N. R. M. Cossi, J. M. Millam, M. Klene, J. E. Knox, J. B. Cross, C. A. V. Bakken, J. Jaramillo, R. Gomperts, R. E. Stratmann, A. J. A. O. Yazyev, R. Cammi, C. Pomelli, J. W. Ochterski, K. M. R. L. Martin, V. G. Zakrzewski, G. A. Voth, J. J. D. P. Salvador, S. Dapprich, A. D. Daniels, J. B. F. O. Farkas, J. V. Ortiz, J. Cioslowski, and D. J. Fox, Gaussian 09, Inc., Wallingford CT, 2013.

20 S. F. Boys and F. Bernardi, Mol. Phys., 2006, 19, 553-566.
21 R. F. W. Bader, Atoms in Molecules: A Quantum Theory, Oxford University Press, Oxford, 1994.

22 F. Biegler-Konig and J. Schonbohm, J. Comput. Chem., 2002, 23, 1489-1494.

23 A. E. Reed, L. A. Curtiss and F. Weinhold, Chem. Rev., 1988, 88, 899-926.

24 E. D. Glendening, C. R. Landis and F. Weinhold, J. Comput. Chem., 2013, 34, 1429-1437.

25 T. Lu and F. W. Chen, J. Comput. Chem., 2012, 33, 580-592.

26 W. Humphrey, A. Dalke and K. Schulten, J. Mol. Graphics, 1996, 14, 33-38.

27 A. Bondi, J. Phys. Chem., 1964, 68, 441-451.

28 I. V. Alabugin, K. M. Gilmore and P. W. Peterson, Wiley Interdiscip. Rev.: Comput. Mol. Sci., 2011, 1, 109-141.

29 L. Goodman, H. B. Gu and V. Pophristic, J. Phys. Chem. A, 2005, 109, 1223-1229.

30 S. Wolfe, Acc. Chem. Res., 1972, 5, 102-111.

31 S. Scheiner, S. J. Grabowski and T. Kar, J. Phys. Chem. A, 2001, 105, 10607-10612.

32 G. Narayszabo and G. G. Ferenczy, Chem. Rev., 1995, 95, 829847.

33 P. Politzer, J. S. Murray and T. Clark, Phys. Chem. Chem. Phys., 2010, 12, 7748-7757.

34 J. S. Murray and P. Politzer, Wiley Interdiscip. Rev.: Comput. Mol. Sci., 2017, 7, e1326.

35 J. S. Murray, S. Ranganathan and P. Politzer, J. Org. Chem., 1991, 56, 3734-3737.

36 R. F. W. Bader, M. T. Carroll, J. R. Cheeseman and C. Chang, J. Am. Chem. Soc., 1987, 109, 7968-7979.

37 E. R. Johnson, S. Keinan, P. Mori-Sanchez, J. ContrerasGarcia, A. J. Cohen and W. Yang, J. Am. Chem. Soc., 2010, 132, 6498-6506.

38 J. Contreras-Garcia, W. T. Yang and E. R. Johnson, J. Phys. Chem. A, 2011, 115, 12983-12990.

39 A. Otero-de-la-Roza, E. R. Johnson and J. Contreras-Garcia, Phys. Chem. Chem. Phys., 2012, 14, 12165-12172.

40 R. Chaudret, B. de Courcy, J. Contreras-Garcia, E. Gloaguen, A. Zehnacker-Rentien, M. Mons and J. P. Piquemal, Phys. Chem. Chem. Phys., 2014, 16, 9876-9891.

41 U. Koch and P. L. A. Popelier, J. Phys. Chem., 1995, 99, 97479754.

42 I. Rozas, I. Alkorta and J. Elguero, J. Am. Chem. Soc., 2000, 122, 11154-11161. 